\title{
GRAMSCI, O CAPITAL SUPRANACIONAL E O NOVO TEOREMA DA POLÍTICA
}

\section{Alex Fiúza de Mello}

No curso da modernidade - e como um de seus pilares imagéticos - a teoria política clássica (séculos XVII-XIX) acostumou-nos a pensar a sociedade, sua dinâmica e sua configuração, nos horizontes da territorialidade (social, econômica, política) predominantemente nacional. A sociedade civil, o Estado, o governo, a soberania, a democracia, a República, as formas de contrato, as leis, a dominação, a hegemonia, a liberdade, a cidadania, a cultura, a identidade - são todos conceitos consagrados nos contornos e sob a égide da idéia arquetípica de nação, marco referenciallimite e consciência possível das perspectivas então projetadas de efetivação de um tipo de engenharia política arquitetada numa escala superior de ordenamento social. Este é o fundamento teórico básico e comum a alguns dos mais emi-

Artigo recebido em janeiro/2006

Aprovado em julbo/2006 nentes representantes dessa tradicional politologia, como Bodin, Hobbes, Locke, Montesquieu, Rousseau, Tocqueville, Renan e tantos outros.

Não muito diferente, foi também a Nação, na moldura do século XX, o prisma que orientou hegemonicamente todo o olhar. "Desde um ponto de vista sentimental e ideológico - destaca Elias -, a Nação, organizada como Estado [...], apresentase como o valor supremo [...], aparece como eterna, como imutável em seus traços essenciais de caráter, [em relação à qual] as mudanças históricas [parecem] afetar unicamente ao exterior" (Elias, 1993, pp. 24-25). Deste viés, extensivo a todas as latitudes ideológicas, não escapou nem mesmo o marxismo. Leslie Sklair, que elaborou no início da década passada uma Sociologia do sistema global, faz menção ao fato de que, desde a década de 1960 até os dias de hoje, o principal do marxismo tem sido, em maior ou menor grau, fortemente "estadocentrado", como bem ilustra a tese da "autonomia relativa do Estado" e todas as conse- 
qüências teóricas daí derivadas - por certo interessantes e frutíferas, mas que têm fechado, em contrapartida, outras importantes avenidas para a teoria e a pesquisa.

Todos continuam a priorizar o sistema dos Estados-nação [argüi Sklair], a recuar sobre ele para descrever o que acontece no mundo, e para explicar como e por que as coisas acontecem. O renascimento da sociologia histórica desde os anos de 1970, por exemplo, apoderou-se amplamente da idéia do "trazer o Estado de volta à cena" [descurando de acentuar, com maior rigor, outras formas fenomênicas de manifestação do capitalismo que, àquela altura, já alçavam patamares mais complexos de materialidade] [...]. [E ainda que] não possamos [certamente] ignorar o Estado-nação, [temos, contudo, que atentar para uma] concepção de sistema global baseado sobre práticas transnacionais (Sklair, 1991, pp. 5-6).

Não é sem propósito, pois, que Gramsci reputado por Perry Anderson como o mais importante teórico do marxismo ocidental - tenha sido apropriado, muitas vezes, em certos circuitos acadêmicos e políticos, como um teórico da "questão nacional", quando muito um estrategista de um comunismo regional, perdendo-se de vista, em conseqüência, circuitos dialéticos mais complexos e criativos de sua teoria política (e de sua heurística) e a atualidade potencial de sua contribuição para as ciências sociais contemporâneas, particularmente no que tange ao desafio comum de deslindamento dos fenômenos inerentes ao processo de globalização em curso, suas múltiplas manifestações, contradições e materialidade societária.

Gramsci, essencialmente - este é o núcleo do argumento -, é um teórico da mundialização da política; observador e analista do advento de uma formação progressivamente planetária de civiltà. Herdeiro direto do pensamento de Marx, concebe o capitalismo, simultaneamente, como um modo de produção e como processo civilizatório geneticamente engravidados de mundialidade. A produção da mundialidade - a mundialização - revelase, nesse diapasão, aspecto essencial da lei de movimento da civilização do capital - do processo de reprodução ampliada da acumulação -, na medida em que, sem o seu concurso, os outros fundamentos da sociedade burguesa - sua condi- ção de modo de produção de mercadorias e de mais-valia - careceriam da possibilidade de sua própria efetividade.

De fato, para Marx, a percepção do processo de mundialização embutido na dinâmica do capital, desde a expansão quinhentista do comércio ultramarino (capital comercial) até as primeiras manifestações mais evidentes, no Oitocentos, do regime de concentração/centralização de suas bases produtivas (capital industrial), apresenta-se não somente como um dado histórico - devidamente registrado e relevado - mas, também, como lei sociológica intrínseca de seu movimento, com base na qual todo o potencial de seu dinamismo, então manifesto, assim como as tendências de seu desenvolvimento futuro já vinham sendo devidamente equacionados. E não são poucas, muito menos secundárias, as passagens na obra do autor de $O$ capital em que os horizontes desse entendimento ganham destaque:

Foi a grande indústria que criou verdadeiramente a história mundial na medida em que fez depender do mundo inteiro cada nação civilizada e, para a satisfação das suas necessidades, cada indivíduo dessa nação, destruindo o caráter exclusivo das diversas nações que era até então natural (A ideologia alemã).

Por meio da exploração do mercado mundial, a burguesia deu um caráter cosmopolita à produção e ao consumo em todos os países, retirando da indústria, para desespero dos reacionários, sua base nacional. As antigas indústrias nacionais foram aniquiladas e o são ainda todos os dias $(O$ manifesto comunista).

[...] o [atual] desenvolvimento das forças produtivas implica que a existência empírica atual dos homens decorra no âmbito da história mundial e não no da vida local [...] tornando cada um deles dependente dos restantes e fazendo com que, finalmente, os homens empiricamente universais vivam de fato a história mundial, em vez de serem indivíduos vivendo numa esfera exclusivamente local ( $A$ ideologia alemâ).

[...] a tendência para criar o mercado mundial está dada diretamente no próprio conceito de capital (Grundrisse). 
[...] o mercado mundial é o verdadeiro ser, a verdadeira base e a atmosfera em que vive o modo capitalista de produção (O capital, vol. 3).

Em lugar do antigo isolamento local e da autosuficiência das nações, desenvolvem-se, em todas as direções, um intercâmbio e uma interdependência universais (O manifesto comunista).

[O capital] criou por todos os lados as mesmas relações entre as classes da sociedade, destruindo por isso o caráter particular das nacionalidades [...]. A grande burguesia surge como uma classe cujos interesses são os mesmos em todas as nações e para a qual a nacionalidade deixa de existir ( $A$ ideologia alemã).

Com o rápido aprimoramento de todos os meios de produção, com as imensas facilidades dos meios de comunicação, a burguesia arrasta todas as nações, mesmo as mais bárbaras, para a civilização [...]. Força todas as nações a adotarem o modo burguês de produção; força-as a adotarem o que ela chama de civilização, isto é, a se tornarem burguesas. Em uma palavra, cria o mundo à sua imagem ( $O$ manifesto comunista $)$.

Capital é somente um outro nome para civilização (Grundrisse).

Gramsci comunga desse recorte de leitura do capitalismo, de sua arquitetônica moldura mundial, mais do que nunca translúcida no cenário de sua época de militância; e está atento aos movimentos de reformatação dos patamares contemporâneos de sociabilidade e de institucionalidade, mediados pela crescente interseção e interpenetração entre o local, o nacional e o mundial - por relações, estruturas e processos articulados em padrões e escalas dinamicamente superiores ao da era prémoderna. Seja em seus escritos de juventude, como, em seqüência, nos Cadernos do cárcere, três dimensões analíticas, a esse respeito, podem ser destacadas, sugerindo uma releitura atenta de seus conceitos e formulações: uma, de cunho mais epistemológico; outra, de conteúdo histórico-sociológico; por fim, uma dimensão de natureza filosófico-política, voltada à análise das tendências do devir na presente contemporaneidade.

Para Gramsci, o mundo havia se tornado uma realidade empiricamente objetiva, dinamica- mente perceptível, a revolucionar o locus da observação e o paradigma da compreensão dos fenômenos hodiernos. A perspectiva da mundialidade, imposta pela força dos acontecimentos, provocara uma verdadeira ruptura epistemológica em relação aos quadros teóricos de referência herdados do período pré-iluminista e, mesmo, do naciocentrismo, pelo Iluminismo, engendrado. No intuito de sintetizar o que fora tal "revolução científica" para a sua geração, assim expressara-se Engels, poucos anos antes, em texto lapidar:

O mundo tornara-se, subitamente, quase dez vezes maior; em vez do quadrante de um hemisfério, era o Globo inteiro que se apresentava ao olhar pasmado dos europeus ocidentais, que se apressaram a apoderar-se dos outros sete quadrantes. E com as velhas fronteiras estreitas de sua pátria caíram também as barreiras milenárias do modo de pensamento medieval estabelecido (Engels, 1973, p. 117).

Representante dessa tradição marxista, Gramsci, no segundo quartel do século XX, reavivará o tema do "mundo" - dir-se-ia hoje, da "sociedade global" - e potencializa-o a partir da ótica de quem não mais vislumbrava apenas o nascimento de uma sociedade que progressivamente se mundializava, mas na condição de sujeito que já experimentava os primeiros efeitos concretos e avassaladores desse processo. O mundo tornara-se, definitivamente, uma realidade econômica e social tout court; uma entidade sociológica sui generis:

Três anos de guerra [diz Gramsci] trouxeram muitas modificações ao mundo. Mas esta é, talvez, a maior de todas as modificações: três anos de guerra tornaram sensivel o mundo. Nós sentimos o mundo; antes só o pensávamos. Sentíamos o nosso pequeno mundo, éramos participantes das dores, das esperanças, das vontades, dos interesses do pequeno mundo no qual estávamos mergulhados mais diretamente. Soldavamo-nos à coletividade mais vasta só com um esforço de pensamento, com um enorme esforço de abstração. Agora a soldagem tornou-se mais íntima [...]. A universalidade do pensamento concretizou-se, tende, pelo menos, a concretizar-se. Alguma coisa desaba necessariamente em nós e nos outros. Formou-se um clima moral novo: tudo se move, tudo é instá- 
vel, fluido [...]. E nasce o caos, a confusão das línguas, e cruzam-se as propostas mais disparatadas com as mais luminosas verdades. Expiamos assim a nossa ligeireza de ontem, a nossa superficialidade de ontem. Desabituados a pensar, contentes com a vida do dia-a-dia, encontramo-nos hoje desarmados contra a tempestade. Tínhamos mecanizado a vida, tínhamo-nos mecanizado a nós próprios [...]. Maior é, pois, o dever atual de pôr uma ordem em nós. O mundo aproximou-se de nós, mecanicamente, por impulsos e forças que nos eram estranhos (Gramsci, 1977a, p. 161)

Gramsci é testemunha das profundas transformações então em operação no contexto da civilização burguesa e preanuncia o surgimento de estruturas econômicas e políticas do capital em geral, em escala global, numa espécie de avant-première de um filme que se projetaria algumas décadas depois. Já em 1918 tematizava o significado da Liga das Nações, uma das primeiras materializações institucionais supranacionais de um sistema capitalista em franca evolução em direção de um reordenamento mais intenso e cada vez mais interdependente em plano e escala mundiais. Assim argumenta em seu artigo "A liga das nações":

Para a burguesia, Liga das Nações quer dizer dissolução das relíquias políticas do feudalismo. A economia burguesa, num primeiro momento, dissolveu as pequenas nacionalidades, os pequenos grupos feudais; libertou os mercados internos de todas as peias mercantis que embaraçavam o tráfico, que impediam que a produção se transformasse e se expandisse. A economia burguesa suscitou, assim, as grandes nações modernas. Nos países anglo-saxões, ultrapassou esta posição; a prática liberal criou, no interno, maravilhosas individualidades, energias seguras e aguerridas para a luta e para a concorrência, descentralizou os Estados, desburocratizou-os; a produção, não insidiada continuamente por forças não econômicas, desenvolveu-se com um respirar de amplitude mundial, despejou nos mercados mundiais montes de mercadorias e de riqueza. Continua a operar; sente-se sufocada pela sobrevivência do protecionismo em muitos mercados europeus e do mundo [...]. Neste período de vida do mundo lança a ideologia da Liga das Nações. Ela representa para a burguesia liberalista anglo-saxônica a garantia política da atividade econômica de amanhã e do ulterior desenvolvimento capitalista.
É a tentativa para adequar a política internacional às necessidades das trocas internacionais [...]. É o grande estado burguês supernacional que dissolveu as barreiras alfandegárias, que ampliou os mercados, que ampliou o respirar da livre concorrência e que permite as grandes empresas, as grandes concentrações capitalistas internacionais (Gramsci, 1977b, pp. 188-189, grifos meus).

No século XX, na arena de um capitalismo definitivamente mundializado, o local e o nacional - eis o salto dialético! - já estão subsumidos a planos societários mais complexos, que pouco a pouco vão moldando as formas de institucionalidade, pelo sistema, requeridas, enquanto fases múltiplas de combinações regionais, internacionais e supranacionais se sucedem até que se formem as condições de uma economia segundo um plano mundial. Aliás, a configuração de uma estruturação da economia mundial formada por blocos de nações é uma tese que também está presente nos Quaderni, formulação precursora de significativo valor histórico e sociológico:

Os acordos políticos regionais poderiam tornar-se acordos econômicos regionais, em virtude dos quais a importação e a exportação "negociadas" não se verificariam mais apenas entre dois Estados, mas entre um grupo de Estados, eliminando muitos inconvenientes não pequenos, evidentíssimos [...]. Esta tendência política poderia ser a forma moderna de Zollverein, que levou ao Império germânico federal, ou das tentativas de liga alfandegária entre os Estados italianos antes de 1848, e, avançando mais, do mercantilismo do século XVII. E poderia tornar-se a etapa intermediária da "Pan-Europa" de Briand, na medida em que ela corresponde a uma exigência das economias nacionais sem perderem o caráter nacional. O mercado mundial, segundo esta tendência, seria constituído de uma série de mercados não mais nacionais, mas internacionais (interestatais), que organizariam no seu interior certa estabilidade das atividades econômicas essenciais e que poderiam relacionar-se entre si à base do mesmo sistema [...]. São todas hipóteses ainda muito vagas, mas que devem se levadas em conta ao estudar-se o desenvolvimento das tendências acima referidas (Gramsci, 1978, pp. 209-210).

Gramsci chama a atenção para o fato de que, no plano mundial - isto é, na efetivação de 
uma sociabilidade definitivamente transnacionalizada (pelo capital) -, as instâncias de materialização e ordenamento societários compõem uma totalidade contraditoriamente articulada, em que as partes se condicionam reciprocamente e se interdeterminam continuamente funções no interior de uma dinâmica em permanente transformação interativa entre "moléculas" e "organismos". Portanto, no plano da história, cada situação, tomada na sua particularidade ou genericidade, pode ser pensada como uma espécie de "bloco histórico", em que os momentos (e as formas) se confundem recíproca, horizontal e verticalmente, combinando-se e dividindo-se de maneira alternada conforme cada conjuntura:

[...] é preciso levar em consideração que com as relações internas de um Estado-nação se entrelaçam as relações internacionais, criando novas combinações originais e historicamente concretas. Uma ideologia, nascida em um país mais desenvolvido, difunde-se em países menos desenvolvidos, incidindo no jogo local das combinações (Idem, 1975a, vol. 3, Q. 13 (17), p. 1585).

É com base nessa premissa que Gramsci vai esboçar uma série de questionamentos de inestimável valor heurístico, que permitem evidenciar, com rara clareza, o estágio de elaboração teórica a que ele havia chegado a respeito das transformações operadas pela formação social capitalista em escala mundial - e suas implicações de natureza política:

Será ainda possível, no mundo moderno, a hegemonia cultural de uma nação sobre as outras? Ou já estará o mundo de tal modo unificado na sua estrutura econômico-social, que um país, ainda que podendo ter "cronologicamente" a iniciativa de uma inovação, não pode, porém, conservar o "monopólio político" e, portanto, servir-se de tal monopólio como base de hegemonia? Qual o significado que ainda pode ter hoje o nacionalismo? Não será ele possível apenas como "imperialismo" econômico-financeiro e não mais como "primado" civil ou hegemonia político-intelectual? (Idem, Q. 13 (26), p. 1618, grifo meu).

Esse conjunto de perguntas, intimamente conectadas, não apenas representa um amplo e prio- ritário programa de pesquisa proposto pelo autor (ao seu estilo, como tantos outros temas dessa forma sugeridos ao longo de sua obra), como mapeia os horizontes possíveis que havia alcançado em suas elaborações teóricas, atento que era ao desenvolvimento dos acontecimentos de seu tempo e às possibilidades dos desdobramentos históricos potencialmente presentes nesses fenômenos contemporâneos. De fato, o trecho destacado está prenhe de revelações e potencializa, de forma condensada e sintética, a percepção sociológica que Gramsci tinha da dinâmica civilizatória do capitalismo, de sua capacidade de expansão e transfiguração, da historicidade de suas estruturas e da mobilidade de sua institucionalidade. A passagem é ilustrativa e oferece contornos propícios para se penetrar no âmago do raciocínio gramsciano, em seu esforço de deslindamento das novas formas de ordenação e funcionamento do universo social burguês, então em fase de rearticulações processuais/institucionais/ societárias (em termos econômicos, políticos e culturais) ampliadas em escala mundial.

O desenvolvimento do Estado-nacional, do nacionalismo, da unificação social num plano superior ao dos principados tradicionais, é momento evolutivo, é desenvolvimento bistórico, passagem do simples ao complexo, avanço do processo de universalização societária, amadurecimento da genericidade humana, possibilidade da construção de outros níveis de consciência social capazes de aproximar os homens entre si, de unificação da humanidade. Mesmo quando Gramsci se volta para os problemas inerentes ao processo político da unificação italiana, portanto para as especificidades do contexto peninsular que apresentava suas equações originais - esta a razão primordial, estratégica e politicamente urgente da elaboração sistemática de sua teoria sobre a "questão nacional" (e, no âmbito desta, a "questão meridional") -, jamais perde de vista que toda relação de hegemonia ultrapassa as fronteiras de uma nação, envolvendo relações mais complexas, de base mundializada:

Toda relação de hegemonia é necessariamente uma relação pedagógica e se verifica não apenas no interior de uma nação, entre as diversas forças que a compõem, mas em todo o campo internacional e mundial, entre conjuntos de civiliza- 
ções nacionais e continentais (Idem, vol. 2, Q. 10 (44), p. 1331, grifos meus).

Tal formulação aponta para a necessidade de uma apropriação mais rica do conceito de hegemonia, o qual, embora não tenha sido desenvolvido suficientemente por Gramsci na análise das relações internacionais - como fora no caso nacional -, apresenta-se como categoria de potencial heurístico atualíssimo e disponível para incursões teóricas arrojadas no deslindamento das novas formas de exercício do poder em escala mundial. Não é ao acaso que, na passagem dos Quaderni em que se refere ao Estado como "organismo próprio de um grupo, destinado a criar as condições favoráveis à expansão máxima desse grupo [...] [e de] desenvolvimento de todas as energias "nacionais", Gramsci aspeia o termo "nacionais", ao se referir às energias movimentadas pela ação estatal na busca de consolidação do projeto hegemônico. A adjetivação encontra sua decifração mais refinada se prosseguimos a leitura do argumento iniciado: "[...] É ainda necessário levar em consideração que, com essas relações internas, a um Estado-nação se entrelaçam relações internacionais, criando novas combinações originais e historicamente concretas" (Idem, vol. 3, Q. 13 (17), pp. 1584-1585, grifos meus).

Gramsci está atento às transformações do capitalismo (seus surtos de mundialização) - e certamente tem presente os novos questionamentos lançados pela teoria leninista do imperialismo - ao apontar as modificações na natureza das relações internacionais, seja no campo da economia, da política, seja, num sentido amplo, da cultura. As novas relações internacionais de força transitam circuitos que, mais do que extrapolam, condicionam a instância "nacional", criando um campo inédito de interatividade, de formas organizativas, de relações econômicas, de efetividade do exercício do poder, de institucionalidade estatal, de reelaborações simbólicas, de linguagem, de visões de mundo, em suma, de realização da hegemonia. É somente dentro dessa problemática mais geral como argüi Spinella:

[...] válida para toda uma fase histórica e para todos os países capitalistas, [que] se determinam também numerosas particularidades nacionais [...] seja em nível das forças produtivas, como das relações de produção, [seja], por último, à realidade complexa e variada das instituições e da cultura (1977, p. 13).

A delimitação, assim, do que passa então a ser concebido como "nacional" ou "internacional", "local" ou "mundial", "oriente" ou "ocidente" ganha conotações de cunho muito mais metodológico (categorias como ferramentas de análise) do que propriamente de clivagem histórico-geográfica; conceitos que, quando analisados, demonstram ser "nada mais que uma 'construção' convencional, isto é, 'histórico-cultural". Uma ilustração dessa penetração transversal entre internacional e nacional, redefinindo combinações originais nos diversos níveis de institucionalidade, é dada ainda por Gramsci quando analisa possíveis transformações nas estruturas e nas funções partidárias no âmbito de situações que envolvem circuitos mais complexos de relações de poder, como aqueles perpassados por interesses supranacionais:

Quanto mais a vida econômica imediata de uma nação está subordinada às relações internacionais, tanto mais um determinado partido representa esta situação e a explora para impedir o predomínio dos partidos adversários [...]. Desta série de fatos se pode concluir que, freqüentemente, o assim denominado "partido estrangeiro" não é propriamente aquele que como tal é vulgarmente indicado, mas exatamente o partido mais nacionalista, o qual, em realidade, mais do que representar as forças vitais do próprio país, representa a subordinação e o servilismo econômico às nações ou a um grupo de nações hegemônicas (Gramsci, 1975a, vol. 3, Q. 13 (2), pp. 1512-1513).

Aqui, mais uma vez, mesmo trabalhando no interior da esfera conceitual das nacionalidades, Gramsci, mais do que atenua, subordina as fronteiras aparentes que tradicionalmente reduziram, a uma simples lógica "cartográfica", o significado de "nacional" e "estrangeiro", contrapondo que, diferente e substancialmente, são os interesses de classe - entendidos como conjunto de articulações que recobrem um universo de interesses supranacionais e despatriados - o compasso que demarca o mapeamento do terreno político, a "técnica" de classificação do loteamento do real. 
Para Gramsci, as contradições a mover indivíduos e estruturas já se apresentavam de tal ordem espraiadas e condensadas em circuitos supranacionais (e não apenas no contexto europeu) que os aparentemente localizados acontecimentos passavam a ser irremediavelmente mediados por níveis sempre mais complexos de causalidades, transversalmente incidentes, sistemicamente subsumidos. Tal constatação lhe conduzira a concluir, à época, que a revolução (comunista) passara a ser uma necessidade na Itália mais por motivos internacionais do que por aqueles inerentes ao processo de desenvolvimento do aparelho de produção nacional (cf. Gramsci, 1977c, p. 66).

Os reformistas e todo o bando dos oportunistas [argüi] têm razão quando dizem que na Itália não existem as condições objetivas da revolução: têm razão porque falam e pensam como nacionalistas, porque concebem a Itália como um organismo independente do resto do mundo e concebem o capitalismo italiano como fenômeno puramente italiano. Não concebem o internacionalismo como realidade vivente e operante na história, tanto do capitalismo como do proletariado [...] [e] a realidade italiana como inserida num sistema internacional, como dependente deste Sistema (Idem, ibidem).

Tal é o caráter (e a razão de ser) da Internacional, nas suas várias versões. Há muito, pelo menos desde o século XIX, o raio "nacional" referencial da ordem econômica e política já vinha sendo suplantado pelo diâmetro-mundo. A mesma burguesia que suscitou as grandes nações modernas, num dado momento do processo de mercantilização de todas as coisas e da constituição da civilização da mais-valia, ultrapassou esta posição e desenvolveu-se com um respirar de amplitude mundial, estádio do qual, portanto, "o proletariado, educado no socialismo, começará a sua história", herdando das condições objetivas criadas "O impulso para alcançar aquela maturidade econômica que, segundo Marx, é a condição necessária para o coletivismo" (Idem, 1977d, p. 164).

É nessa perspectiva que a luta revolucionária é concebida como uma

[...] luta pela objetividade (para libertar-se das ideologias parciais e falazes) e esta luta é a própria luta pela unificação cultural do gênero humano. [Pois] aquilo que os idealistas denominam de "espírito" não é um ponto de partida, mas de chegada, o conjunto das superestruturas em devenir em direção à unificação concreta e objetivamente universal (Idem, 1975a, vol. 2, Q. 11 (17), p. 1416).

Tal é o sentido gramsciano da revolução proletária, pensada como revolução máxima; e do por que do movimento político "nacional" ter de ser uma expressão do movimento internacional - razão, por sinal, das críticas radicais do marxista italiano ao Partido Socialista de seu país (o PSI), na conjuntura do ano de 1920:

O partido esteve ausente do movimento internacional. A luta de classes está assumindo em todos os países do Mundo formas gigantescas; os proletários são impulsionados, por toda a parte, a renovar os métodos de luta e, freqüentemente, como na Alemanha depois do golpe de força militarista, a sublevarem-se com as armas na mão. O partido não procura explicar ao povo trabalhador italiano estes acontecimentos, justifica-os à luz da concepção da Internacional Comunista, não procura desenvolver toda uma ação educativa destinada a tornar consciente o povo trabalhador italiano desta verdade: que a revolução proletária é fenômeno mundial e que cada um dos acontecimentos deve ser julgado num quadro mundial (Idem, 1977e, p. 133, grifos meus).

A sociedade, como o homem - formulara Gramsci nos idos de 1918 -, "é sempre e apenas uma unidade histórica e ideal que se desenvolve negando-se e superando-se continuamente" (Idem, 1982, p. 644). Na dialética desse devir, a unificação do mundo, objetiva e concreta, torna-se condição para a unidade futura do gênero humano, o pressuposto material que viabiliza o reencontro, num patamar superior, do indivíduo com a coletividade. O capitalismo, como formação social historicamente mais evoluída (e resultado monumental do trabalho acumulado), é a ponta avançada de todo esse processo civilizatório, cujo ethos, porém, referente à fase de sua acumulação ampliada, "só se afirmará [completamente] como formula Oliveiros Ferreira - quando os indivíduos, pela trama das relações sociais, se afastarem da natureza e identificarem seu espaço social 
com o espaço econômico planetário do modo de produção" (Ferreira, 1986, p. 85). Somente então estarão criadas as bases à emergência de uma nova subjetividade que, finalmente, perseguirá a cidadania mundial.

Da mesma forma que Renan se empenhava, ao final do século XIX, em traduzir a singularidade histórica do fenômeno nacional - por ele denominado "modernas autonomias européias" - que, como configuração sócio-político-institucional, apenas começava a moldar-se de forma mais sólida no mundo europeu - arcabouço de originais mecanismos de solidariedade e institucionalidade desconhecidos da era pré-moderna (Renan, 1983) -, Gramsci teoriza sobre o mundo de sua contemporaneidade (quarenta anos depois de Renan) chamando a atenção para a internacionalização das relações econômicas, políticas e culturais então em curso, fundantes de um novo patamar de sociabilidade, de relações de poder e de subjetividade, ao qual as nacionalidades - sem desaparecer - passam a estar subsumidas e condicionadas. O sentido de internacionalização é tomado no seu significado processual, como movimento histórico que lança as bases de uma mundialidade societária emergente, com suas estruturas e superestruturas supranacionais, no interior da qual as nações passam a representar condensações particulares das contradições mais complexas da civiltà planetária. Tal qual Marx (e Lênin), Gramsci percebe o capitalismo como momento de desenvolvimento de uma civilização mundial, que deverá ser completado pelas realizações da revolução proletária (nas suas várias formas e vias), que ele acreditava estar em andamento. Por isso é que "a forma superior da civilização capitalista [...] desemboca na forma da sociedade coletivista, na qual a ilusão se tornará factibilidade" (Gramsci, 1975b, pp. 323-324).

Essa perspectiva de universalização histórica da cultura humana (que não pode ser mecânica e stalinianamente dividida entre "cultura burguesa" e "cultura operária") - e que encontra na idade burguesa os fundamentos ontológicos de sua objetivação em um nível de efetividade que se torna praticamente "irrenunciável" - fornece o ângulo estratégico a partir do qual Cerroni irá defender a existência, nos Quaderni, de uma "teoria geral da cultura" (Cerroni, 1978) e, em conseqüência, o imperativo da universalização (leia-se: mundializa- ção) da política. A observação é justa quando se leva em consideração que a idéia de história, em Gramsci, coincide com a de processo civilizatório, ou seja, com a de desenvolvimento progressivo e tendencialmente universalizante dos padrões de sociabilidade humana, neles incluídas não somente a morfologia da vida econômica e política de uma formação social, mas também as representações coletivas (culturais) e suas várias expressões filosóficas, científicas, literárias e artísticas. Apenas sob tal espectro de leitura do real é que se pode entender a solução dada por Gramsci à sua própria questão do "por que também os marxistas oficiais 'combinaram' o marxismo com uma filosofia não-marxista”. ${ }^{2}$

O mundo, como tal, é definitivamente um fato sociológico. É um novo "teorema" a operar sínteses distintas daquelas emergidas no início do movimento de expansão da sociedade mercantil burguesa, ainda hoje presentes nos múltiplos e sutis contrabandos teóricos naciocêntricos. São novos os códigos de interatividade a gestar, em proporções dinâmicas mais ampliadas - dada a interconexão mais complexa do mercado e das culturas -, inéditas equações para o sentido de "local", "nacional" e "internacional", em permanente reterritorialização (lógica e histórica), da mesma forma que para os parâmetros cartográficos da política, seus fundamentos e desenhos institucionais.

O debate atual sobre "globalização" envolve, no limite, uma disputa pela hegemonia mundial. Uma verdadeira "guerra de posição". Desafia a formulação de um paradigma teórico que informe e forme gerações, presentes e futuras, sobre uma idéia de mundo; mundo que estão, empiricamente, herdando e que são desafiados a dar continuidade. Sinaliza, portanto, um embate cultural mais amplo pela internalização de uma visão de mundo, pela criação de um receptáculo ideológico que molde mentalidades, pela capacidade de dirigir utopias e destinos, apontando e convencendo ora que a história "chegou ao fim" (e que as democracias liberais e a sociedade de mercado encarnam o estádio terminal do devir histórico), ora que ela apenas inicia um novo capítulo do desenvolvimento humano, pleno de possibilidades, capaz de oferecer, potencialmente, "a solução ao conflito entre homem e natureza, entre homem e homem 
[...] entre existência e essência, entre objetivação e auto-afirmação, entre liberdade e determinismo, entre indivíduo e espécie" (Fromm, 1979, p. 70).

Nesse inédito e planetário campo de guerra, um olhar pelo retrovisor à tradição herdada dos clássicos se torna um imperativo categórico ante o desafio - inadiável - da elaboração de um novo teorema da política. Daí a atualidade de Gramsci.

\section{Notas}

1 A criação de uma definitiva "ordem geral cosmopolita" kantiana.

2 "O marxismo - diz Gramsci - tinha duas tarefas: combater as ideologias modernas na sua forma mais refinada e esclarecer as massas populares, cuja cultura era medieval [...]. Por razões 'didáticas', o marxismo confundiu-se com uma forma de cultura um pouco superior à mentalidade popular, inadequada para combater as outras ideologias das classes cultas, ao passo que o marxismo originário era justamente a superação da mais elevada manifestação cultural do seu tempo, a filosofia clássica alemã" (cf. Gramsci, 1975a, vol. 1, Q. 4 (3), pp. 422-423)

\section{Bibliografia}

CERRONI, U. (1978), "Universalidade + política", in Franco Ferri (coord.), Política e história em Gramsci, publicação do Instituto Gramsci, trad. de Luiz Mário Gazzaneo, Rio de Janeiro, Civilização Brasileira, vol. 1.

ELIAS, N. (1993), El proceso de la civilización. 2 ed. México, Fondo de Cultura Económica.

ENGELS, F. (1973), "A origem da família, da propriedade privada e do Estado", in K. Marx, Sociedade e mudanças sociais (coletânea de textos). 2 ed. Lisboa, Edições 70.

FERREIRA, O. S. (1986), Os 45 cavaleiros húngaros: uma leitura dos Cadernos de Gramsci. São Paulo, Hucitec/Edunb.

FROMM, E. (1979), Conceito marxista do homem. 7 ed. Trad. de Octávio Alvez Velho. Rio de Janeiro, Zahar.
GRAMSCI, Antonio. (1975a), Quaderni del carcere. Edizione critica dell'Istituto Gramsci, a cura di Valentino Gerratana. Torino, Einaudi, 4 vols.

(1975b), "La dittadura democratica" (Il Grido del Popolo, 19/10/1918), in Torino, Einaudi. Scritti Giovanili 1914-1918, (1977a), "Leituras" (Il Grido del Popolo, 24/11/1917), in Escritos políticos, trad. de Manuel Simões, Lisboa, Seara Nova, vol. 1.

(1977b), "A liga das nações" (Il Grido del Popolo), in Escritos politicos, trad. Manuel Simões, Lisboa, Seara Nova, vol. 1

. (1977c), "Os revolucionários e as eleições" (L'Ordine Nuovo, 15/11/1919), in Escritos políticos, trad. Manuel Simões, Lisboa, Seara Nova, vol. 2.

(1977d), "A revolução contra o capital" (Avanti, 24/11/1917), in

Escritos políticos, trad. Manuel Simões, Lisboa, Seara Nova, vol. 1.

(1977e), "Para uma renovação do Partido Socialista" (L'Ordine Nuovo, 8/5/1920), in Escritos políticos, trad. Manuel Simões, Lisboa, Seara Nova, vol. 2.

(1978), Maquiavel, a politica e o Estado moderno. 3 ed. Trad. de Luiz Mário Gazzaneo. Rio de Janeiro, Civilização Brasileira.

(1982), La città futura, 1917-1918. A cura di Sergio Caprioglio. Torino, Einaudi.

RENAN, E. (1983), Que es uma nación? 2 ed. Trad. de Rodrigo Fernández Carvajal. Madri, Centro de Estudios Constitucionales.

SKLAIR, L. (1991), Sociology of the global system. Londres, Harvester \& Wheatsheaf.

SPINELLA. (1977), "Prefácio", in A. Gramsci, Pequeña antologia política. 2 ed. Barcelona, Editorial Fontanella. 
GRAMSCI, O CAPITAL SUPRANACIONAL E O NOVO TEOREMA DA POLÍTICA

Alex Fiúza de Mello

Palavras-chave: Gramsci; Marxismo; Capitalismo; Mundialização da política.

Gramsci é um autor da atualidade, teórico da mundialização do capitalismo, mas ainda desconhecido, mesmo no campo do marxismo, entre as suas tendências dominantes. Pensar a globalização, o século XXI, a nova conjuntura política nos quadros da contemporaneidade é um desafio intelectual da maior relevância que tem, em Gramsci - certamente para surpresa de uns e negação de outros -, uma de suas fontes mais estimulantes e reveladoras. É fascinante desvendar em seus escritos teses indispensáveis para refletirmos alguns dos principais temas do momento em horizontes mundiais.

\section{GRAMSCI, SUPRANATIONAL CAP- ITAL, AND THE NEW THEOREM OF POLITICS}

Alex Fiúza de Mello

Keywords: Gramsci; Marxism; Capitalism; Globalization of politics.

Gramsci is a current author and theorizer of the globalization of capitalism, though still unknown, even in the field of Marxism, amongst its dominant tendencies. Thinking globalization, the twenty-first century, as well as the new political conjuncture amid contemporaneity, is a most relevant intellectual challenge that has in Gramsci - for surprise of some and denial of others - one of its most stimulating and revealing sources. It is fascinating to unveil in his writings theses that are essential in order to reflect some of the most relevant current themes in global horizons.
GRAMSCI, LE CAPITAL SUPRANATIONAL ET LE NOUVEAU THÉORÈME DE LA POLITIQUE

Alex Fiúza de Mello

Mots-clés: Gramsci ; Marxisme ; Capitalisme ; Mondialisation de la politique.

Gramsci est un auteur d'actualité, théoricien de la mondialisation du capitalisme, mais qui demeure peu connu, même parmi les tendances dominantes du marxisme,. Penser la globalisation, le $\mathrm{XXI}^{e}$ siècle, la nouvelle conjecture politique dans le cadre de la contemporanéité, cela constitue un défi intellectuel de la plus grande importance et qui possède, dans Gramsci - certainement à la surprise de certains et la négation d'autres -, une de ses sources les plus stimulantes et révélatrices. Il est fascinant de dévoiler, dans ses écrits, des thèses indispensables à la réflexion de certains des principaux thèmes d'actualité par rapport à des horizons mondiaux. 